\title{
Higher BMI in Childhood: The Contributory Factor For Type 2 Diabetes and Cardiovascular Disease in Adulthood
}

\author{
Manju Dewan
}

\begin{abstract}
Aim: To study obesity related risks of cardiovascular diseases (CVD) and type 2 diabetes in children. Method: Present study was carried out on 2048 children (boys and girls). BMI categories help to diagnose risks for cardiovascular disease and type 2 diabetes in children. Results: In this study of 2048 children, $6.84 \%$ are exposed to moderate risk of cardiovascular Diseases (CVD) and type 2 diabetes and $1.66 \%$ are at high risk of CVD and type 2 diabetes. The risk is higher in the children of urban population as compared to that of rural population. The risk is also higher in boys than in girls. Conclusion: There is the tendency that obese children may grow into obese adults. These risks increase with increasing age of the children. More emphasis should be made on the maintenance of normal weight amongst in order to prevent future health risks.
\end{abstract}

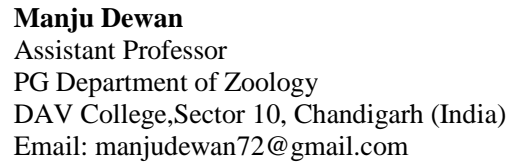

Key Words: BMI, Health risks, Obesity, Overweight, CVD

DOI: $10.18376 / j e s p / 2018 / v 14 / i 1 / 111297$

Introduction: BMI is a useful parameter of overweight and obesity. It is an estimate of body fat and a good measure to diagnose risk for diseases that can occur with overweight and obesity. BMI is the standard metric for determining normal-weight, overweight and obese categories. Childhood obesity may also lead to significant health problems like type -2 diabetes, asthma, sleep apnea, psychological stress, including low self-esteem caused by the social stigma of being obese (Ul-Haq et al, 2014 and Nuttall et al,2015).People with BMIs higher than 30 are at increased risk of dying from variouschronic diseases. Childhood obesity has emerged as one of the most serious public health issues of the 21 st century (Malik et al, 2013). Epidemiological studies have shown a substantial increase in the risk of disease with elevated BMI (i.e. severe or morbid obesity) (Kitahara et al,2014). Obese children are more likely to become obese adults. Adult obesity is associated with a number of serious health risks.

\section{Materials and Method}

2048 Children and adolescent aged 10-19 years were selected randomly for questioning regarding the different aspects of epidemiology.Body mass index or BM, was measuredbythe criterion used by Lambert Adolphe Jacques Quetelet, a Belgian astronomer, mathematician, statistician and sociologist.BMI Categories were used to determine various health risks (WHO Singapore declaration on Asian Population, 2005):

$<18.5 \quad$ Nutritional Deficiency and Osteoporosis

18.5-22.9 Healthy Range

23.0-27.5 Moderate risk for cardiovascular disease and Type 2 diabetes

>27.5 High risk for cardiovascular disease and Type 2 diabetes 


\section{Results and Discussion}

According to the Centers for Disease Control and Prevention (CDC), obesity can put at a greater risk for health conditions like type 2 diabetes, high blood pressure, joint problems, and gallstones (American Heart Association, 2016 and Overweight and Obesity Statistics, 2017).WHO Singapore declaration on Asian Population, 2004 had indicated that BMI should always be interpreted in terms of cardiovascular diseases (CVD) and type-2 diabetes. In this study $6.84 \%$ subjects are exposed to moderate risk of CVD and type- 2 diabetes and $1.66 \%$ are at high risk of CVD and type 2 diabetes (Table 1 and graph 1). The risk is higher in children of urban population as compared to that of rural population. The risk is also higher in boys than in girls (Graph 2\& 3). In an another study conducted by Mohanty (2008) in Pondicherry, $4.5 \%$ subjects were exposed to moderate risk of CVD and type 2 diabetes and nobody was found to be at high risk of CVD and type 2 diabetes. The risk was also higher in urban population as compared to rural population. Maintaining a healthy weight during childhood is especially important for leading a free life during adulthood.

Table 1: BMI Categories according to health risk

\begin{tabular}{|c|c|c|c|c|}
\hline $\begin{array}{l}\text { Group/Sub } \\
\text { Group }\end{array}$ & $\begin{array}{l}\text { Below } 18.5 \quad \mathrm{~N} \\
(\%)\end{array}$ & $\begin{array}{l}18.5-22.9 \quad \mathrm{~N} \\
(\%)\end{array}$ & $\begin{array}{l}\text { 23.0-27.5N } \\
(\%)\end{array}$ & $\begin{array}{l}\text { Above } 27.5 \quad \text { N } \\
(\%)\end{array}$ \\
\hline All Data & $1357(66.26 \%)$ & $517(25.24 \%)$ & $140(6.84 \%)$ & $34(1.66 \%)$ \\
\hline Urban & $622(61.16 \%)$ & $272(26.75 \%)$ & $95 \quad(9.34 \%)$ & $28(2.75 \%)$ \\
\hline Rural & $735(71.29 \%)$ & $245(23.76 \%)$ & $45 \quad(4.36 \%)$ & $\begin{array}{ll}6 & (0.58 \%) \\
\end{array}$ \\
\hline & \multicolumn{4}{|c|}{$\mathrm{Chi}^{\wedge} 2=42.82^{* *}(\mathrm{df}: 3) \mathrm{C}=0.14$} \\
\hline Male & $918(64.69 \%)$ & $360(25.37 \%)$ & $29 \quad(2.04 \%)$ & $112(7.89 \%)$ \\
\hline Female & $439(69.79 \%)$ & $157(24.96 \%)$ & $28 \quad(4.45 \%)$ & $\begin{array}{ll}5 & (0.79 \%)\end{array}$ \\
\hline & \multicolumn{4}{|c|}{$\mathrm{Chi}^{\wedge} 2=13.38 * *(\mathrm{df}: 3) \mathrm{C}=0.08$} \\
\hline
\end{tabular}

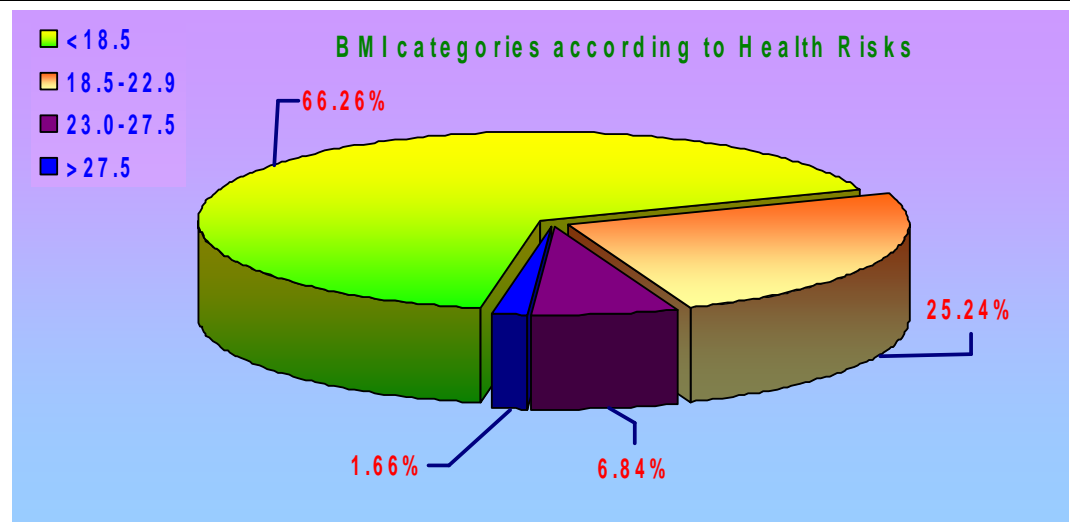

Figure 1: BMI categories according to health risks 


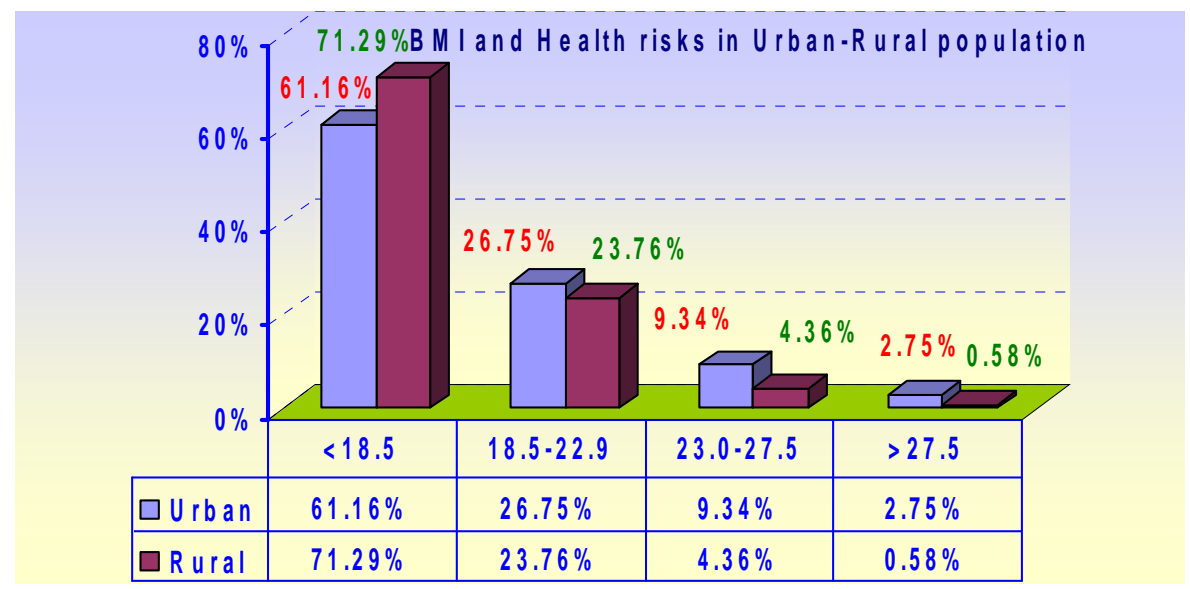

Figure 2:BMI and Health risks in urban and rural population

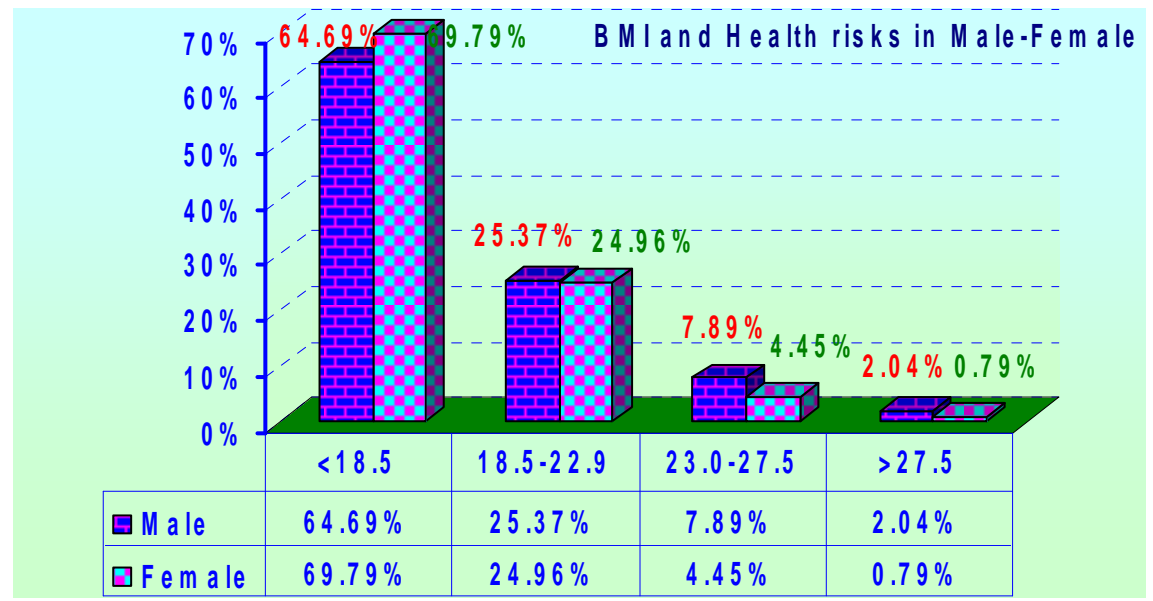

Figure 3: BMI and Health risks in male and female population

Overweight and obesity are increasing globally. Many Asian populations used to be physically active with a low body mass index (BMI), but the region now has some of the world's highest rates of obesity (WHO,2004) . BMI is associated with several health problems like high blood pressure (Chen et al,2013), heart disease (Ganz et al 2014), Type 2 Diabetes Pereira-Mirandaet al,2017 and Mental Health ( Lewington et al,2009). Waist circumference is just as accurate at measuring someone's cardiorespiratory fitness as BMI andthese both measurements could estimate the risk of heart disease (Flint et al,2010 and Dua at al, 2014).According to Ganz et al 2014, BMI of 35 or greater can cause twice likely to die from cardiovascular disease.According to Pereira-Mirandaet al, 2017 , being overweight may boost your odds for type- 2 diabetes by 50 percent. The risk gets greater as BMI increases. Having a higher BMI lead to symptoms of depressionand generally a lower sense of well-being. One review of nine studies found that obese were 32 percent more likely to have depression as compared to healthy weight folks (Lewington et al, 2009). All major international guidelines recommend weight loss and lower BMI level associated with lowest 


\section{Journal of Exercise Science \& Physiotherapy, Vol. 14, No. 1 (January to June), 2018 \\ ISSN: 0973-2020 (Print) I I OR Impact Factor = 5.23 UGC Approved [no.7485] ISSN: 2454-6089 (Online)}

mortality in patients having hypertension (Mancia et al, 2013 and James et al, 2014).The largest mean increases in BMI over the period show strong relationship with the increase greatest in urban settlements Whereas several studies have identified higher mean BMI or proportion overweight in urban areas (Monteiro et al,2000, Martorell et al,2000 and Dearth-Wesley et al,2008). Obesity is associated with an increased risk of cardiovascular disease and may be associated with more severe coronary artery disease (CAD); however, the relationship between BMI $\left(\mathrm{kg} / \mathrm{m}^{2}\right)$ and CAD severity is uncertain and debatable. The CDC recommends losing 5 to 10 percent of current body weight, which can decrease the blood pressure, blood sugar, and cholesterol (Centers for Disease Control and Prevention ,2018). Wang et al (2013) obtained information of 10957 elderly hypertensive patients from an electronic health record system and followed them for a median of 3.7 years. They found that underweight, rather than overweight and obesity was associated with all-cause mortality. In Taiwan Longitudinal Study on Aging, which was conducted from 1996 to 2007, a subgroup analysis of middle-aged and older patients with hypertension $(n=985)$ found an inverse association between BMI and all-cause mortality (Chung et al,2015). In a study on Koreans(Jee et al,2006) the risk of death from CVD rose steadily with increasing BMI. According to Chen,2012 study of Chinese men, a $61 \%$ and $48 \%$ increase in stroke and CHD mortality, respectively, was observed for every five unit increase in the upper BMI range (23.5 to 35), whereas no association was observed in the lower range (15 to 23.5). The WHO-recommended BMI cut point of $23 \mathrm{~kg} / \mathrm{m}^{2}$ for Asians. It was associated with higher diabetes prevalence in some Asian groups.According to WHO 2000\&2004, Asian BMI cut points of $23 \mathrm{~kg} / \mathrm{m}^{2}$ for overweight and $27.5 \mathrm{~kg} / \mathrm{m}^{2}$ for obesity may cause better health impact and can reduce the risk of type- 2 diabetes and CVD.

Overweight children tend to protect themselves from negative comments and attitudes by retreating to safe places, such as their homes, where they may seek food as a comfort. In addition, children who are overweight tend to have fewer friends than normal weight children, which results in less social interaction and play and they spent more time in sedentary activities. As aforementioned, physical activity is often more difficult for overweight and obese children as they tend to get shortness of breath and often have a hard time keeping up with their peers. This in turn inevitably results in weight gain, as the amount of calories consumed exceeds the amount of energy burned (Niehoff, 2009).Higher BMI during childhood is associated with an increased risk of CHD in adulthood. The associations are stronger in boys than in girls and increase with the age of the child in both sexes. Risk factors for coronary heart disease (CHD), such as hypertension, dyslipidemia, impaired glucose tolerance, and vascular abnormalities, are already present in overweight children.Children are becoming heavier worldwide; greater numbers of them are at risk of having CHD in adulthood(Jennifer et al, 2007). The present study indicated the effects of childhood BMI in relation to gender and urban and rural population. Further more studies are needed to find out the associations of BMI ,type -2 diabetes and CHD and to determine that higher BMI values in childhood are associated with a greater risk of CHD in adulthood.Long-term effects of excess childhood weight can remain unknown. These risks increase with increasing age of the children.

Conclusion: If children are overweight, obesity in adulthood is likely to be more severe. This study highlights the need for more investigations to prevent unexpected increases of BMI and subsequently future explosions in non-communicable diseases reducing life expectancy and increasing health costs. More emphasis should be made on the maintenance of normal weight amongst in order to prevent future health risks.

\section{Acknowledgement}

The author is highly thankful to UGC for providing grant for undertaking the research award. 


\section{References}

American Heart Association. Understanding the American Obesity Epidemic. . March 9, 2016. Anne B. Gregory, Kendra K. Lester, Deborah M. Gregory, Laurie K.Twells, WilliamK. Midodzi .The Relationship between Body Mass Index and the Severity of Coronary Artery Disease in Patients Referred for Coronary Angiography Cardiology Research and Practice Volume 2017 (2017), Article ID 5481671, 10 pages.

Centers for Disease Control and Prevention. Losing Weight. January 2018

Chen Z, Yang G, Offer A, Zhou M, Smith M, Peto R, et al. Body mass index and mortality in China: a 15-year prospective study of 220000 men. Int J Epidemiol2012; 41: 472-81.

Chen Y, Copeland W, Vadanthan R, et al. Association between Body Mass Index and Cardiovascular Disease Mortality in East Asians and South Asians: Pooled Analysis of Prospective Data From the Asia Cohort Consortium. British Medical Journal. October 2013.

Chung WS, Ho FM, Cheng NC, Lee MC, Yeh CJ.. BMI and all-cause mortality among middleaged and older adults in Taiwan: a population-based cohort study. Public Health Nutr. $2015 ; 18: 1839-46$.

Dearth-Wesley T, Wang H, Popkin B. Under-and overnutrition dynamics in Chinese children and adults (1991-2004). Eur J Clin Nutr 2008;62:1302-7.

Dua S, Bhuker M, Sharma P, et al. Body Mass Index Relates to Blood Pressure Among Adults. North American Journal of Medical Sciences. February 2014.

Flint A, Rexrode K, Hu F, et al. Body Mass Index, Waist Circumference, and Risk of Coronary Heart Disease: A Prospective Study Among Men and Women.Obesity Research and Clinical Practice. July-September 2010.

Ganz M, Wintfeld N, Li Q, et al. The Association of Body Mass Index with the Risk of Type 2 Diabetes: A Case-Control Study Nested in an Electronic Health Records System in the United States. Diabetology \& Metabolic Syndrome. September 2014.

James PA, Oparil S, Carter BL, Cushman WC, Dennison-Himmelfarb C, Handler J, et al.2014 evidence-based guideline for the management of high blood pressure in adults: report from the panel members appointed to the Eighth Joint National Committee (JNC 8). JAMA. 2014; 311:507-20.

Jennifer L. Baker, Ph.D., Lina W. Olsen, Ph.D., and Thorkild I.A. Sørensen, M.D., Dr. Med .Sci.Childhood Body-Mass Index and the Risk of Coronary Heart Disease in AdulthoodN Engl J Med. 2007 Dec 6; 357(23): 2329-2337.

Kitahara CM, Flint AJ,de Gonzalez AB et al. . Association between class III obesity (BMI of 40$59 \mathrm{~kg} / \mathrm{m}^{2}$ ) and mortality: a pooled analysis of 20 prospective studies. PLoS Med 2014; 11.

Jee SH, Sull JW, Park J, Lee SY, Ohrr H, Guallar E, et al. Body-mass index and mortality in Korean men and women. N Engl J Med2006; 355:779-87.

Lewington S, MacMahon S, Peto R. Body-Mass Index and Cause-Specific Mortality in 900,000 Adults: Collaborative Analyses of 57 Prospective Studies. The Lancet. March 2009.

Malik VS, Willett WC,Hu FB.Global obesity: trends, risk factors and policy implications. Nat Rev Endocrinol 2013, 9:13-27.

Mancia G, Fagard R, Narkiewicz K, Redon J, Zanchetti A, Böhm M, et al. 2013 ESH/ESC guidelines for the management of arterial hypertension: the Task Force for the Management of Arterial Hypertension of the European Society of Hypertension (ESH) and of the European Society of Cardiology (ESC). Eur Heart J. 2013; 34:2159-219. 10.1093/eurheartj/eht151.

Martorell R, Khan LK, Hughes ML, Grummer-Strawn LM. Obesity in women from developing countries. Eur J Clin Nutr 2000;54:247-52. 
Mohanty, B. The prevalence of overweight and obesity in school going children of Pondicherry. 2007-2008. Study sponsored by Department of science and Technology and Environment, Govt. of Pondicherry.

Monteiro CA, D'A Benicio MH, Conde WL, Popkin BM. Shifting obesity trends in Brazil. Eur J Clin Nutr 2000; 54:342-6.

Niehoff V. Childhood obesity: A call to action. Bariatric Nursing and Surgical Patient. Care. 2009;4:17-23.

Nuttall, F. Body Mass Index: Obesity, BMI, and Health A Critical Review. Nutrition Today. MayJune 2015.

Overweight and Obesity Statistics. National Institute of Diabetes and Digestive and Kidney Diseases. August 2017.

Pereira-Miranda E, Costa P, Queiroz VAO, et al. Overweight and Obesity Associated with Higher Depression Prevalence in Adults: A Systematic Review and Meta-Analysis. Journal of the American College of Nutrition. March-April 2017.

Quetelet Adolphe (1796-1874)--the average man and indices of obesity". Nephrology, Dialysis, Transplantation. 23 (1): 47-51.

Ul-Haq Z, Mackay D, Fenwick E, Pell J. Association Between Body Mass Index and Mental Health Among Scottish Adult Population: A Cross-Sectional Study of 37272 Participants. Psychological Medicine. July 2014.

Wang Y, Wang Y, Qain Y, Zhang J, Tang X, Sun J, et al. Association of body mass index with cause specific deaths in Chinese elderly hypertensive patients: Minhang community study.PLoS One. 2013; 8:e71223. 10.1371.

Women. Obesity. July-September 2010.

World Health Organization, International Association for the Study of Obesity, International Obesity Task Force. Health Communications Australia. 2000. The Asia-Pacific perspective: Redefining obesity and its treatment.

World Health Organization. Appropriate body-mass index for Asian populations and its implications for policy and intervention strategies. Lancet. 2004; 363:157-163.

Woodward M, Huxley H, Lam TH, Barzi F, Lawes CM, Ueshima H. A comparison of the associations between risk factors and cardiovascular disease in Asia and Australasia. Eur J Cardiovascular Prev Rehabil2005;12:484-91. 